\title{
A comparison of experimental designs for cultivar evaluations
}

HAE Saul ${ }^{1,2}$, M Booyse $^{3}$, PA Swanepoel ${ }^{1}$

${ }^{1}$ Department of Agronomy, Stellenbosch University, Private Bag X1, Stellenbosch, 7600

${ }^{2}$ Agricultural Research Council Small Grains Institute, Private Bag X29, Bethlehem, South Africa, 9700

${ }^{3}$ Agricultural Research Council Biometry, Private Bag X5026, Stellenbosch, South Africa, 7600

\section{Abstract}

Spatial heterogeneity and the lack of clear or significant treatment responses in agricultural field experiments complicates recommending the most suitable cultivar(s) to producers for a specific area. Increased attention should be given to the experimental design of cultivar trials, as failure to capture spatial heterogeneity may increase the unexplained variance and thus might influence the accuracy of results. A randomised complete block design (RCBD) is the most popular design in variety trials in South Africa. However, latinised row-column designs (LRCD) is widely recommended in literature for field experimentation, because of the efficiency to control heterogeneity in two dimensions. The aim of this study was to compare the efficiency of RBCD with LRCD and recommend the more appropriate design for use by practitioners in cultivar trials. Wheat (Triticum aestivum) was used as a test crop. An analysis of variance was performed on the data produced from both designs conducted on wheat in the Swartland region of South Africa over a two-year period. An LRCD provided better accuracy and model or design estimations than RCBD. The results demonstrated the value of eliminating variance in two directions rather than one direction. We therefore recommend the use of LRCD in preference to RCBD in variety trials.

Keywords: cultivar trials; latinised row column design; randomised complete block design; variation; wheat 


\section{Introduction}

Spatial heterogeneity is a pervasive feature of natural and agricultural ecosystems, and this often creates a challenge to breeders and agronomists when planning field trials. Field trials play a critical role in breeding and agronomic research. Their main objectives are to accurately measure and predict grain yield and yield components, determine grain yield stability and to provide reliable guidance to select the best genotypes (Crossa 1990). Increased attention should be given to the experimental design of multi-location field trials, as this might influence the accuracy of results. A randomised complete block design (RCBD) is a popular design in field trials in South Africa. Agronomists and plant breeders prefers a RCBD for field experimentation because of its simplicity and familiarity (Vargas et al. 2013). However, this design is inadequate to capture large spatial variability, because it does not consider the presence of spatial variability within blocks. In order to improve accuracy of data generated from field trials, and to limit variation caused by external factors, it is important to make sure blocks are uniform and, in that way, minimise the plot-to-plot variation. However, as in many areas across South Africa, in the Western Cape the landscape and soil type, texture, depth and stone content are highly variable and it is challenging to identify a homogenous area for field trials (Swanepoel et al. 2019), RCBD does not capture all spatial variability, since the blocks capture heterogeneity in one direction (Piepho et al. 2015).

Latinised row-column design (LRCD) has the advantage of combating spatial variability through blocking in two directions (Williams et al. 2006). In LRCDs, treatments are assigned once to a row, and once to a column, and replicated. When variety trials are laid out in a rectangular array of latinised rows and columns with 
replicates allocated contiguously, analysis can be performed to improve the precision of estimates of cultivar effects and cultivar contrasts (Burgueno et al. 2002).

There is a serious paucity of information to inform about the most suitable design for South African conditions. The LRCD is widely recommended in literature for field experimentation, because of the efficiency to control heterogeneity in two dimensions (Piepho et al. 2016). Yet it is seldom used in South African field trials. The aim of this study was to compare the efficiency of RBCD with LRCD and recommend the more appropriate design for use by practitioners in cultivar trials using. Wheat (Triticum aestivum) was used as a test crop.

\section{Materials and methods}

Research site

The experiment was carried out over two years (2014 and 2015) on the farm Klein Swartfontein, situated three kilometres outside of Moorreesburg in the Western Cape

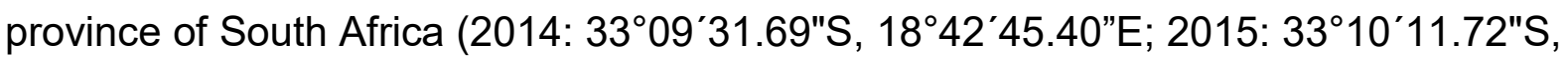
$018^{\circ} 43^{\prime} 22.05^{\prime \prime}$ ). The area has a Mediterranean-type climate with average daily temperatures ranging between $17^{\circ} \mathrm{C}$ in winter and $29^{\circ} \mathrm{C}$ in summer. The average annual rainfall is $320 \mathrm{~mm}$, but may vary between 250 and $600 \mathrm{~mm}$. The landscape is undulating, usually with clay-loamy soil textures. Soil forms in this region are mostly Glenrosa or Clovelly soil forms (Soil Classification Working Group 1991). The farming system for the past 15 years involved Conservation Agriculture integrated with livestock. Wheat is the main cash crop. The experimental field was within a three-year crop rotation system with a sequence of wheat followed by two years of annual medic (Medicago spp.) pastures. 


\section{Experimental designs and treatments}

Two trials were planted adjacent to each other. In the first trial, 14 wheat cultivars were tested as treatments laid out in RCBD, replicated in four blocks. In the second trial, the same 14 cultivars were evaluated in a latinised row-column design, replicated in four blocks (Figure 1). The randomised field layout for the both designs were produced by CycDesigN (Whitaker et al. 2002).

The trials of both designs were planted on 14 May 2014 and again on 22 May 2015, which is within the optimal planting window for the region. Planting was done using an Ausseeder DBS multi-stream conservation-tillage planter with a row spacing of 300 $\mathrm{mm}$. Plot size comprised $5 \times 2 \mathrm{~m}$, and each plot had seven rows of wheat. Although 14 cultivars were included in each year, two cultivars that were planted in 2014 were replaced by other cultivars in 2015 . For the analyses conducted on the combined years (2014 and 2015), only the 12 corresponding cultivars were included.

\section{Trial management}

Soils samples were collected prior to planting to depth of $200 \mathrm{~mm}$ to determine the soil nutrient status. Soil test results were used to determine the fertiliser programme, and therefore only one representative soil sample, consisting of eight subsamples, were collected per trial. At planting $40 \mathrm{~kg}$ nitrogen, $11 \mathrm{~kg}$ phosphorus and $5 \mathrm{~kg}$ potassium was applied per hectare. A split application of $20 \mathrm{~kg} \mathrm{~N}$ was applied at stem elongation and another $40 \mathrm{~kg} \mathrm{~N}$ between flag leaf and pre-heading stages.

Pre-emergent herbicides (800 $\mathrm{g} \mathrm{L}^{-1}$ prosulfocarb and triasulfuron at $750 \mathrm{~g} \mathrm{~kg}^{-1}$ ) was applied at recommended dosage rate to ensure a clean seedbed. Insecticide $(222 \mathrm{~g}$

$\mathrm{L}^{-1}$ acetamiprid /acetamidine) and/or fungicides (62.5 $\mathrm{g} \mathrm{L}^{-1}$ epoxiconazole and $310 \mathrm{~g} \mathrm{~L}^{-}$ 1 thiophanate) were applied depending on type of infestation. 
Randomised complete block design

\begin{tabular}{|l|l|l|l|l|l|l|l|l|l|l|l|l|l|}
\hline \multicolumn{10}{|c|}{ Block 2} \\
\hline 13 & 14 & 7 & 2 & 5 & 1 & 6 & 8 & 12 & 3 & 4 & 11 & 10 & 9 \\
\hline 10 & 4 & 12 & 5 & 1 & 3 & 7 & 2 & 14 & 8 & 6 & 9 & 13 & 11 \\
\hline \multicolumn{10}{|c|}{ Block 3 } \\
\hline 3 & 4 & 10 & 6 & 9 & 11 & 13 & 8 & 12 & 1 & 5 & 7 & 2 & 14 \\
\hline \multicolumn{10}{|c|}{ Block 4 } \\
\hline 5 & 12 & 14 & 1 & 2 & 3 & 4 & 10 & 13 & 7 & 9 & 6 & 8 & 11 \\
\hline
\end{tabular}

Latinised row-column design

\begin{tabular}{|c|c|c|c|c|c|c|c|}
\hline \multicolumn{1}{|c|}{$\begin{array}{c}\text { row/ } \\
\text { column }\end{array}$} & 1 & 2 & 3 & 4 & 5 & 6 & 7 \\
\hline 1 & 3 & 2 & 12 & 13 & 4 & 10 & 11 \\
\hline 2 & 7 & 1 & 5 & 9 & 14 & 6 & 8 \\
\hline \multicolumn{7}{|c|}{ Block 2 } \\
\hline $\begin{array}{c}\text { row/ } \\
\text { column }\end{array}$ & 1 & 2 & 3 & 4 & 5 & 6 & 7 \\
\hline 1 & 12 & 6 & 13 & 14 & 2 & 11 & 3 \\
\hline 2 & 8 & 4 & 7 & 5 & 9 & 1 & 10 \\
\hline \multicolumn{7}{|c|}{ Block 3 } \\
\hline row/ & 1 & 2 & 3 & 4 & 5 & 6 & 7 \\
\hline 1 & 9 & 8 & 4 & 1 & 10 & 12 & 13 \\
\hline 2 & 14 & 3 & 2 & 6 & 11 & 7 & 5 \\
\hline \multicolumn{7}{|c|}{ row/ } \\
column
\end{tabular}

Figure 1: Field layout for a radomised complete block desing (top) and a latinised row-column design (bottom) for two adjacent wheat cultivar evaluation trials with 14 cultivars, replicated in four blocks. 


\section{Data collection}

Harvesting started when grain moisture content was between 11 and $14 \%$, and when all cultivars reached physiological maturity. Harvesting was done using a Wintersteiger Nursery Master Elite combine harvester with a $1.2 \mathrm{~m}$ operating width. To determine grain yield, only the middle-five rows were harvested to eliminate any border effects, and weighed. Grain samples were transported to a grain laboratory where they were cleaned of all unwanted, foreign material, straw and chaff. Cleaning was done using a Wintersteiger MLN sample cleaner. Hectolitre mass was determined by using a Dicky John GAC 2100 grain analysis instrument.

\section{Statistical analyses}

The data of the randomised block design was analysed according the layout. The model fitted to the data of the LRCD was analysed according to Gilmour et al. (1995). Normality of standardised residuals was confirmed by Shapiro-Wilk test (Shapiro and Wilk 1965). Bartlett's test was used to verify homogeneity of genotype and year variances (Bartlett 1937). The data were subjected to analysis of variance (ANOVA) using General Linear Models Procedure (PROC GLM) of SAS software (Version 9.4; SAS Institute Incorporated Cary, USA). The Mixed Procedure (PROC MIXED) with the restricted maximum likelihood (REML) method, and Satterthwaite approximation for the denominator degrees of freedom, was performed to calculate variance components and auxiliary verification. Multiple genotype mean comparisons were conducted using least squared means (LSMEANS) with the Tukey adjustment method. The following linear mixed model was fitted for the randomised complete block design: 


$$
Y_{i j k}=\mu+K_{i}+B\left(K_{i j}\right)+G_{k}+G Y_{i k}+\epsilon_{i j k}
$$

where: $\quad Y_{\mathrm{ijk}}=$ observed yield or hectolitre mass

$\mu=$ general mean

$K_{i}=$ effect of the year $B\left(K_{i j}\right)=$ effect of block within year

$\mathrm{G}_{\mathrm{k}}=$ effect of the kth genotype

$\mathrm{GK}_{\mathrm{ik}}=$ interaction effect of the genotype and year

$€_{\mathrm{ijk}}=$ error or residual effect

Year $\left(K_{i}\right)$ and year within block $\left[B\left(K_{i j}\right)\right]$ were specified as fixed and $G_{k}$ and $G K_{i k}$ were specified as random.

The following linear mixed model was fitted for the latinised row column design

$$
Y_{i j k l m}=\mu+K_{i}+B\left(K_{i j}\right)+B R\left(K_{i j k}\right)+B C\left(K_{i j i}\right)+G_{m}+G K_{i m}+\epsilon_{i j k m}
$$

where: $\quad Y_{\mathrm{ijkl}}=$ observed yield or hectolitre mass

$\mu=$ general mean

$K_{i}=$ effect of the year

$B\left(K_{i j}\right)=$ effect of block within year

$B R\left(K_{i j k}\right)=$ effect of block and row within year

$\mathrm{BC}\left(\mathrm{K}_{\mathrm{ijl}}\right)=$ effect of block and column within year

$\mathrm{G}_{\mathrm{m}}=$ effect of the genotype

$\mathrm{GK}_{\mathrm{im}}=$ interaction effect of the genotype and year

$€_{\mathrm{ijklm}}=$ error or residual effect 
Year $\left(\mathrm{K}_{\mathrm{i}}\right)$ and year within block $\left[\mathrm{B}\left(\mathrm{K}_{\mathrm{ij}}\right)\right]$, year within block and row $\mathrm{BR}\left(\mathrm{K}_{\mathrm{ijk}}\right)$ and year within block and column $\mathrm{BC}\left(\mathrm{K}_{\mathrm{ijk}}\right)$ were specified as fixed and $\mathrm{G}_{\mathrm{k}}$ and $\mathrm{GK}_{\mathrm{im}}$ were specified as random.

The variance component calculation from PROC GLM are as follows:

$$
\begin{gathered}
\sigma_{G}^{2}=\frac{\text { MS(en })- \text { MS(Yearxen })}{r S} \\
\sigma_{G Y}^{2}=\frac{\text { MS(Yearxen })- \text { MSE }}{r} \\
\sigma^{2}=\text { MSE }
\end{gathered}
$$

where: $M S(G e n)=$ mean square of genotype

$$
\begin{aligned}
& \text { MS (YearxGen })=\text { mean square of interaction between year and genotype } \\
& \text { MSE = mean square error } \\
& r=\text { the number of blocks } \\
& S=\text { the number of years. }
\end{aligned}
$$

Repeatability of mean grain yield for both designs were calculated according to formulae proposed by Piepho and Möhring (2007) and Falconer and MacKay (1996):

$$
\begin{gathered}
h^{2}=\frac{\sigma_{G}^{2}}{\sigma_{P}^{2}} \\
\sigma_{P}^{2}=\sigma_{G}^{2}+\frac{1}{S} \sigma_{G Y}^{2}+\frac{1}{r} \sigma_{E}^{2}
\end{gathered}
$$

where: $\quad \sigma^{2} p=$ phenotypic variance

$\sigma^{2} G=$ variance of the genotypes

$\sigma^{2} G Y=$ variance of the interaction of genotype by year

$\sigma^{2} E=$ error variance

$r=$ number of blocks

$s=$ number of years 
The repeatability of the plot grain yield for both designs were calculated as described by Pakendorf (1977):

$$
\begin{gathered}
\mathrm{t}=\frac{\sigma_{G}^{2}}{\sigma_{P t}^{2}} \\
\sigma_{P t}^{2}=\sigma_{G}^{2}+\sigma_{G Y}^{2}+\sigma_{E}^{2}
\end{gathered}
$$

Where $\quad \sigma^{2} \mathrm{pt}=$ total or phenotypic variance

$$
\sigma^{2} G=\text { variance of the genotypes }
$$

Relative Efficiency (RE) of two designs are calculated as follows:

$$
R E(L R C D \text { to } R C B D)=\frac{\left(\mathrm{DF}_{L}+1\right)}{\left(D F_{R}+1\right)} \frac{\left(D F_{R}+3\right)}{\left(D F_{L}+3\right)} \times \frac{M S E_{R}}{M S E_{L}}
$$

where $D F L$ and $D F_{R}=$ Degrees of Freedom for $L R C D$ and $R C B D$ respectively. MSE $L$ and $\mathrm{MSE}_{\mathrm{R}}=$ Mean Square Error for $\mathrm{LRCD}$ and $\mathrm{RCBD}$ respectively.

According to Fisher (1926) an RE>1 indicates that the LCRD would be a better design. If the $R E<1$, then RCBD would be the better design.

According to Campbell et al. (2015) the focused identification of experimental significance with Type I errors conceals and restricts the interpretation of cultivar evaluation trial results because Type II errors (the probability of false negative denoted by $ß)$, are ignored. The power of a trial $(1-\beta)$ to detect relevant effects should be calculated. The PROC Mixed output and a procedure described by Campbell et al. (2015) was performed to calculate the power of the designs. 


\section{Results}

The results of the sources of variation for grain yield of the RCBD and LRCD are shown in Table 1. Within a particular year, LRCD produced a smaller trial error (MSE) for grain yield $(M S E=0.05$ in 2014, MSE $=0.07$ in 2015) than that of the RCBD (MSE $=$ 0.07 in 2014 and MSE $=0.09$ in 2015). The smaller error of the LRCD is due to the fact that the nuisance factor (e.g. soil heterogeneity) are removed in two directions by the rows and columns. The RCBD does not have this advantage, thus resulting in a larger error term for the two respective years. In analyses of the combined years for grain yield it is evident that the LRCD performed slightly smaller (MSE of RCBD $=0.07$ vs. MSE of LRCD $=0.06$ ) From the estimated relative efficiency $(R E)$ value of 2014 , 2015 and the two years combined $\left(\mathrm{RE}_{2014}=1.27, \mathrm{RE}_{2015}=1.16\right.$ and $\mathrm{RE}_{\text {combined }}=1.04$, respectively), it is evident that the LRCD is the better design for yield.

The results of the sources of variation for hectolitre mass of the RCBD and LRCD are shown in Table 2. From these results it can be seen that, within a particular year, and even in the analysis of the combined years, RCBD produced a smaller trial error (MSE $=1.06$ in $2014, \mathrm{MSE}=0.84$ in $2015, \mathrm{MSE}=0.88$ for combined years $)$ than that of the LRCD (MSE $=2.08$ in 2014, MSE $=0.53$ in 2015 and MSE $=1.82$ in the combined year analysis). From the estimated $\mathrm{RE}_{2014}=0.46, \mathrm{RE}_{2015}=1.43$ and $\mathrm{RE}_{\text {combined }}=0.43$ it is evident that the RCBD is the better design for hectolitre mass in 2014 and combined years. The LRCD produced better results for hectolitre mass in 2015 .

The grain yield and hectolitre mass trial means for both designs are shown in Table 3 for the two individual years and the years combined. The trial means for grain yield as well as for hectolitre mass produced higher values in the RCBD than in the LRCD but was not significantly different $(p>0.05)$ according to a two-sided t-test with unequal variances. 
Table 1: The source variation of the randomised complete block design (RCBD) and latinised row-column design (LRCD) for the separate and combined years (2014 and 20115) for grain yield (t ha-1) of wheat. DF = Degrees of freedom; SS = Sum of squares; MSE = Mean square error

\begin{tabular}{|c|c|c|c|c|c|c|c|c|c|}
\hline RCBD & & & & & LRCD & & & & \\
\hline & & & & & 2014 & & & & \\
\hline Source & DF & SS & MS & $\mathrm{P}$ & Source & DF & SS & MS & $\mathrm{P}$ \\
\hline Rep & 3 & 0.39 & 0.13 & 0.17 & Rep & 3 & 0.87 & 0.29 & 0.01 \\
\hline & & & & & Row(Rep) & 4 & 0.31 & 0.08 & 0.27 \\
\hline & & & & & Col(Rep) & 23 & 5.12 & 0.22 & 0.01 \\
\hline Genotype & 13 & 10.52 & 0.81 & $<.0001$ & Genotype & 13 & 5.11 & 0.39 & 0.00 \\
\hline Error & 39 & 2.89 & 0.07 & & Error & 12 & 0.64 & 0.05 & \\
\hline Corrected Total & 55 & 13.79 & & & Corrected Total & 55 & 12.05 & & \\
\hline & & & & & 2015 & & & & \\
\hline Source & DF & SS & MS & $\mathrm{P}$ & Source & DF & & MS & $P$ \\
\hline Rep & 3 & 2.09 & 0.70 & 0.00 & Rep & 3 & 0.09 & 0.03 & 0.71 \\
\hline & & & & & Row(Rep) & 4 & 0.73 & 0.18 & 0.08 \\
\hline & & & & & Col(Rep) & 24 & 5.44 & 0.23 & 0.02 \\
\hline Genotype & 13 & 2.95 & 0.23 & 0.01 & Genotype & 13 & 1.27 & 0.10 & 0.26 \\
\hline Error & 39 & 3.34 & 0.09 & & Error & 11 & 0.72 & 0.07 & \\
\hline Corrected Total & 55 & 8.38 & & & Corrected Total & 55 & 8.25 & & \\
\hline & & & & Com & ed 2014-2015 & & & & \\
\hline Source & DF & SS & MS & $\mathrm{P}$ & Source & DF & SS & MS & $\mathrm{P}$ \\
\hline Year & 1 & 40.25 & 40.25 & $<.0001$ & Year & 1 & 42.11 & 42.11 & $<.0001$ \\
\hline Rep(Year) & 6 & 2.07 & 0.34 & 0.00 & Year(Rep*Row) & 14 & 1.92 & 0.14 & 0.09 \\
\hline & & & & & Year(Rep*Col) & 46 & 10.08 & 0.22 & 0.01 \\
\hline Genotype & 11 & 7.11 & 0.65 & $<.0001$ & Genotype & 11 & 3.33 & 0.30 & 0.01 \\
\hline Year*Genotype & 11 & 5.61 & 0.51 & $<.0001$ & Year*Genotype & 11 & 1.81 & 0.16 & 0.06 \\
\hline Error & 66 & 4.78 & 0.07 & & Error & 12 & 0.76 & 0.06 & \\
\hline Corrected Total & 95 & 59.81 & & & Corrected Total & 95 & 60.01 & & \\
\hline
\end{tabular}


Table 2: The source variation of the randomised complete block design (RCBD) and latinised row-column design (LRCD) for the separate and combined years (2014 and 2015) for hectolitre mass $\left(\mathrm{kg} \mathrm{hL}^{-1}\right)$ of wheat. DF = Degrees of freedom; SS = Sum of squares; MS = Mean square error; $P=$ Probability

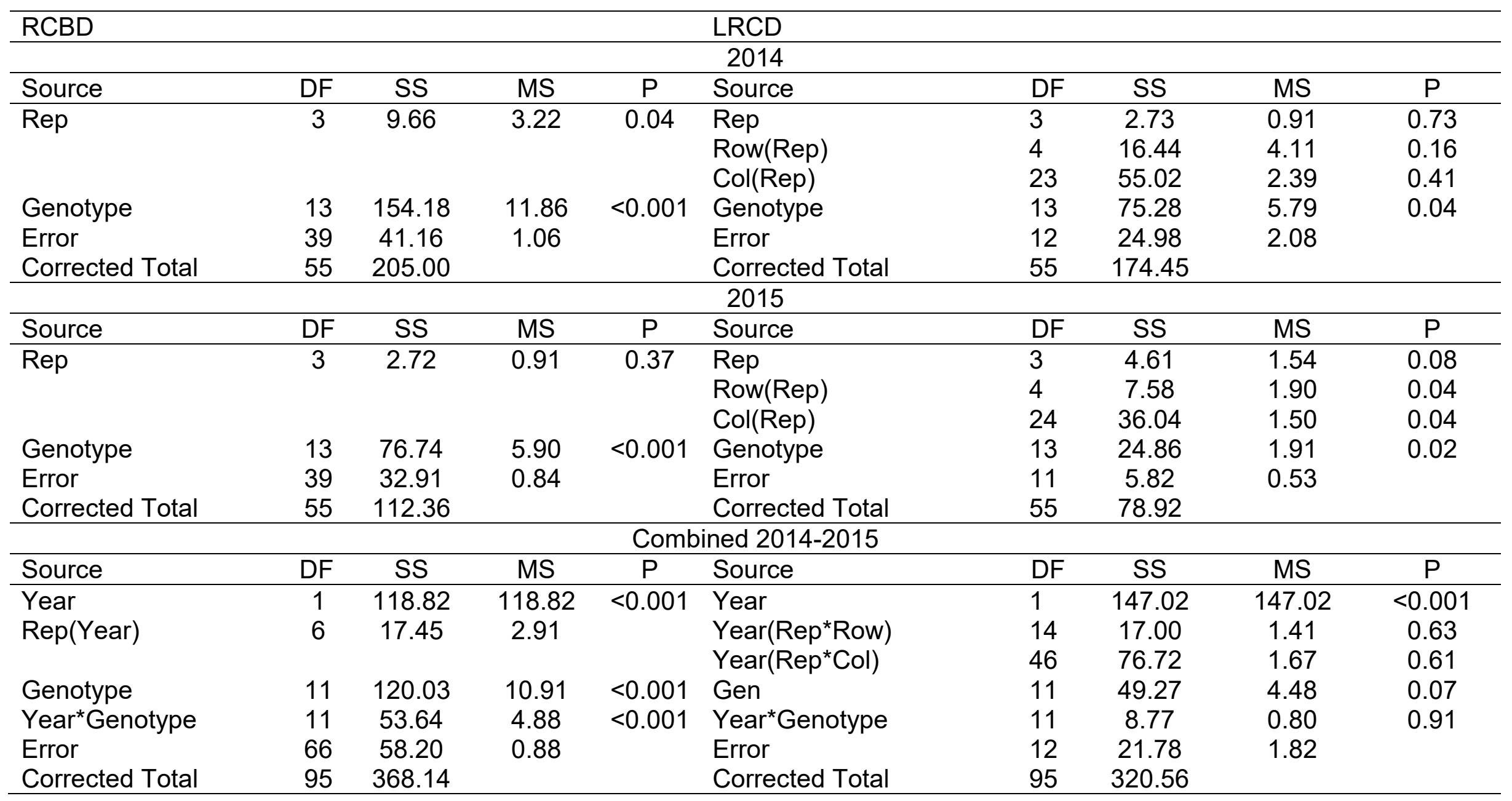


Table 3: Wheat yield and hectolitre mass means for wheat cultivar evaluations conducted in 2014 and 2015, laid out in a latinised row-column design (LRCD) and a randomised complete block design (RCBD). $R^{2}=$ Regression coefficient of determination; $\mathrm{CV}=$ Coefficient of Variation (\%); $\sigma^{2} \mathrm{E}=\mathrm{MSE}=$ Error variance; $\sigma^{2} \mathrm{GY}=$ variance component for genotype by year; $\sigma^{2} G=$ variance component for genotype; $\mathrm{AIC}=$ Akaike information criterion $; \mathrm{BIC}=$ Bayesian information criterion, $\mathrm{BSH}=$ Broad sense heritability; ICC = Inter class correlation

\begin{tabular}{|c|c|c|c|c|c|c|}
\hline & \multicolumn{2}{|c|}{2014} & \multicolumn{2}{|c|}{2015} & \multicolumn{2}{|c|}{ Combined 2014-2015 } \\
\hline & RCBD & LRCD & RCBD & LRCD & RCBD & LRCD \\
\hline $\begin{array}{l}\text { Grain yield } \\
\left(\mathrm{t} \mathrm{ha}^{-1}\right)\end{array}$ & 4.16 & 4.10 & 2.88 & 2.70 & 3.49 & 3.35 \\
\hline $\mathrm{R}^{2}$ & 0.79 & 0.95 & 0.6 & 0.91 & 0.92 & 0.99 \\
\hline CV & 6.54 & 5.72 & 10.16 & 9.38 & 7.71 & 7.51 \\
\hline$\sigma^{2} E$ & 0.07 & 0.05 & 0.09 & 0.07 & 0.07 & 0.06 \\
\hline$\sigma^{2} G$ & 0.18 & 0.08 & 0.04 & 0.01 & 0.02 & 0.02 \\
\hline$\sigma^{2} G Y$ & - & - & - & - & 0.11 & 0.03 \\
\hline $\mathrm{AIC}$ & 57.8 & 29.9 & 47.0 & 15.0 & 90.1 & 77.1 \\
\hline $\mathrm{BIC}$ & 59.1 & 30.8 & 48.3 & 18.0 & 91.5 & 78.0 \\
\hline $\mathrm{BSH}$ & 0.91 & 0.86 & 0.62 & 0.33 & 0.21 & 0.45 \\
\hline ICC & 0.71 & 0.61 & 0.29 & 0.11 & 0.09 & 0.16 \\
\hline $\begin{array}{l}\text { Hectolitre mass } \\
\left(\mathrm{kg} \mathrm{hL}^{-1}\right)\end{array}$ & 78.24 & 78.12 & 79.98 & 80.05 & 78.97 & 78.95 \\
\hline$R^{2}$ & 0.8 & 0.86 & 0.71 & 0.93 & 0.84 & 0.93 \\
\hline CV & 1.31 & 1.85 & 1.15 & 0.91 & 1.19 & 1.71 \\
\hline$\sigma^{2} E$ & 1.06 & 2.08 & 0.84 & 0.53 & 0.88 & 1.82 \\
\hline$\sigma^{2} G$ & 2.7 & 0.93 & 1.26 & 0.35 & 0.75 & 0.46 \\
\hline$\sigma_{G Y}^{2}$ & - & - & - & - & 0.99 & -0.25 \\
\hline $\mathrm{AIC}$ & 196.4 & 74.7 & 178.6 & 49.8 & 311.0 & 176.4 \\
\hline $\mathrm{BIC}$ & 197.7 & 75.6 & 179.9 & 50.7 & 312.5 & 177.0 \\
\hline $\mathrm{BSH}$ & 0.91 & 0.64 & 0.86 & 0.72 & 0.55 & 0.82 \\
\hline ICC & 0.72 & 0.31 & 0.60 & 0.40 & 0.28 & 0.23 \\
\hline
\end{tabular}

The $\mathrm{R}^{2}$ values are parameters to verify how well the data fitted the models. From higher $\mathrm{R}^{2}$ values in LRCD than the values for RCBD in individual years and years combined it could be concluded the LRCD was a better fit for the data than RCBD

The Akaike information criterion (AIC) and Bayesian information criterion (BIC) values are estimators to indicate the best model or design. The smallest AIC or BIC value is 
the best. From Table 3 it is evident that the LRCD provided smaller AIC and BIC smaller values in the individual years (29.9 and 30.8 in 2014; 15.0 and 18.0, respectively) as well as for the combined years (77.1 and 78.0, respectively) compared to that of the RCBD (57.8 and 59.1 in $2014 ; 47.0$ and 48.3 in $2015 ; 90.1$ and 91.5 in the combined years).

The coefficients of variation (CV) for grain yield of the two designs show lower values for LRCD than RCBD in the separate and combined years, which are in agreement with the $\mathrm{R}^{2}$ values. The $\mathrm{CVs}$ for hectolitre mass of the two designs show higher values for LRCD than RCBD in 2014 and combined years, but a lower value in 2015 (Table $3)$.

The RCBD produced higher genotypic variation $\left(\sigma^{2} G=0.18\right.$ and 0.04 in 2014 and 2015, respectively) for grain yield than the LCRD $\left(\sigma^{2} G=0.08\right.$ and 0.01 in 2014 and 2015, respectively). The combined year analyses produced the equal genotypic variance component of 0.02 . The RCBD produced higher genotypic variation $\left(\sigma^{2} G\right)$ for hectolitre mass in the separate years as well as in the combined year analyses.

From the combined year analyses, it is evident that the genotype-by-year $\left(\sigma^{2} G Y\right)$ component for grain yield was larger $(0.11)$ for the RCBD than for LRCD (0.03). From the combined year analyses, it is evident that the genotype-by-year ( $\left.\sigma^{2} \mathrm{GY}\right)$ component for hectolitre mass was larger (0.99) for the RCBD than for LRCD (-0.25).

The mean trial repeatability or broad sense heritability is an indication of how well the trial may be repeated in other years. The broad sense heritability for grain yield of the LRCD was 0.86 and 0.33 in 2014 and 2015, respectively, which are lower than the broad sense heritability of the RBCD (0.91 and 0.62 in 2014 and 2015, respectively). For both years combined, the broad sense heritability for grain yield of LRCD was 
higher $(0.45)$ than that of the RCBD (0.21). The broad sense heritability for hectolitre mass of LRCD was 0.64 and 0.72 in 2014 and 2015, respectively, which are lower than the broad sense heritability of RBCD (0.91 and 0.86 in 2014 and 2015, respectively). For both years combined the broad sense heritability value for hectolitre mass, the LRCD was higher (0.82) than the RCBD (0.55).

The interclass correlation (ICC) is a repeatability measure per plot and one expects values smaller than the broad sense heritability values. The RCBD for grain yield produced higher ICC values of 0.71 in 2014 and 0.29 in 2015 than those of the LRCD (0.61 in 2014 and 0.11 in 2015). For both years combined, the LRCD performed better on a plot repeatability basis of 0.16 versus 0.09 of the RCBD. The RCBD for hectolitre mass produced higher ICC values of 0.72 in 2014 and 0.6 in 2015 than these of the LRCD (0.31 in 2014 and 0.4 in 2015). For both years combined, the RCBD performed slightly better on a plot repeatability basis of 0.28 versus 0.23 of the LRCD.

The least square means for most cultivars for yield showed larger values in the RCBD for the separate and combined years than in the LRCD (Table 4). Similar results were found for hectolitre mass (Table 5).

Statistical power (1-ß), denoting the power of the test among genotypes within a year and combined years, are provided in Table 6. The power estimates are 1.00 for both designs in 2014 and the combined year analyses for both yield and hectolitre mass. The power estimate in 2015 for yield in the RCBD was 0.95 and 0.98 in LRCD. In 2015, the power estimates for hectolitre mass was 1.00 in 2015 for the RCBD and 0.96 for the LRCD. 
Table 4 Least square means ( \pm standard error) of yield for cultivar evaluation trials laid out as a randomised complete block design (RCBD) and a latinised row-column design (LRCD) in the 2014, 2015 and combined years

\begin{tabular}{|c|c|c|c|c|c|c|c|c|}
\hline \multicolumn{3}{|c|}{2014} & \multicolumn{3}{|c|}{2015} & \multicolumn{3}{|c|}{ Combined (2014 - 2015) } \\
\hline Cultivar & RCBD & LRCD & Cultivar & RCBD & LRCD & Cultivar & RCBD & LRCD \\
\hline Kwartel & $3.29 \pm 0.14^{c}$ & $3.97 \pm 0.20 \mathrm{ab}$ & Kwartel & $2.37 \pm 0.15^{b}$ & $2.61 \pm 0.19^{a}$ & Kwartel & $2.83 \pm 0.95^{d}$ & $3.10 \pm 0.20 \mathrm{bcd}$ \\
\hline PAN 3408 & $3.92 \pm 0.14 b c$ & $3.69 \pm 0.21 \mathrm{ab}$ & PAN 3408 & $2.85 \pm 0.15 \mathrm{ab}$ & $2.82 \pm 0.19 a$ & PAN 3408 & $3.39 \pm 0.95 a b c$ & $3.32 \pm 0.20 \mathrm{abcd}$ \\
\hline PAN 3471 & $4.14 \pm 0.14$ ab & $3.91 \pm 0.22 \mathrm{ab}$ & PAN 3471 & $3.18 \pm 0.15^{a}$ & $3.07 \pm 0.20$ & PAN 3471 & $3.66 \pm 0.95 a b$ & $3.38 \pm 0.20 \mathrm{abcd}$ \\
\hline PAN 3515 & $4.19 \pm 0.14 \mathrm{ab}$ & $3.89 \pm 0.18^{a b}$ & SST 0117 & $3.17 \pm 0.15^{a}$ & $2.94 \pm 0.20^{a}$ & Ratel & $3.29 \pm 0.95 b c$ & $3.01 \pm 0.19 \mathrm{~cd}$ \\
\hline Ratel & $3.87 \pm 0.14 b c$ & $3.61 \pm 0.20 \mathrm{ab}$ & Ratel & $2.71 \pm 0.15^{a b}$ & $2.09 \pm 0.20^{a}$ & SST 015 & $3.82 \pm 0.95^{a}$ & $3.60 \pm 0.19 a b$ \\
\hline SST 0127 & $4.72 \pm 0.14 \mathrm{a}$ & $4.59 \pm 0.18^{a}$ & SST 0127 & $2.59 \pm 0.15 \mathrm{ab}$ & $2.81 \pm 0.19 a$ & SST 027 & $3.70 \pm 0.95 a b$ & $3.32 \pm 0.21 \mathrm{abcd}$ \\
\hline SST 015 & $4.51 \pm 0.14^{\mathrm{ab}}$ & $4.38 \pm 0.22 \mathrm{a}$ & SST 0147 & $3.06 \pm 0.15^{a b}$ & $3.04 \pm 0.19 a$ & SST 056 & $3.72 \pm 0.95 \mathrm{ab}$ & $3.57 \pm 0.20 \mathrm{ab}$ \\
\hline SST 027 & $4.33 \pm 0.14 \mathrm{ab}$ & $3.97 \pm 0.18 a b$ & SST 015 & $3.13 \pm 0.15 a$ & $2.77 \pm 0.19^{a}$ & SST 087 & $3.54 \pm 0.95 a b c$ & $3.45 \pm 0.19 a b c$ \\
\hline SST 047 & $4.38 \pm 0.14 a b$ & $4.25 \pm 0.19 a$ & SST 027 & $3.06 \pm 0.15 a b$ & $2.38 \pm 0.20^{a}$ & SST 096 & $3.54 \pm 0.95 a b c$ & $3.36 \pm 0.19 \mathrm{abcd}$ \\
\hline SST 056 & $4.66 \pm 0.14^{a}$ & $4.28 \pm 0.18^{a}$ & SST 056 & $2.78 \pm 0.15 \mathrm{ab}$ & $2.95 \pm 0.19 a$ & SST 88 & $3.14 \pm 0.95 \mathrm{~cd}$ & $2.88 \pm 0.22 d$ \\
\hline SST 087 & $4.22 \pm 0.14 \mathrm{ab}$ & $4.22 \pm 0.24^{a}$ & SST 087 & $2.86 \pm 0.15 a b$ & $2.64 \pm 0.20$ & Tankwa & $3.61 \pm 0.95 a b$ & $3.53 \pm 0.19 a b$ \\
\hline SST 096 & $4.26 \pm 0.14 \mathrm{ab}$ & $3.71 \pm 0.21 \mathrm{ab}$ & SST 096 & $2.82 \pm 0.15^{a b}$ & $2.69 \pm 0.20^{a}$ & SST 0127 & $3.65 \pm 0.95 \mathrm{ab}$ & $3.67 \pm 0.20$ a \\
\hline SST 88 & $3.24 \pm 0.14^{c}$ & $2.84 \pm 0.19 b$ & SST 88 & $3.04 \pm 0.15^{a b}$ & $2.64 \pm 0.20^{a}$ & & & \\
\hline Tankwa & $4.49 \pm 0.14^{a b}$ & $4.40 \pm 0.25 \mathrm{a}$ & Tankwa & $2.72 \pm 0.15^{a b}$ & $2.70 \pm 0.20^{a}$ & & & \\
\hline
\end{tabular}

Means depicted by the same alphabetic letter within a column do not differ significantly $(\mathrm{P}<0.05)$ 
Table 5 Least square means ( \pm standard error) of hectolitre mass for cultivar evaluation trials laid out as a randomised complete block design (RCBD) and a latinised row-column design (LRCD) in the 2014, 2015 and combined years

\begin{tabular}{|c|c|c|c|c|c|c|c|c|}
\hline \multicolumn{3}{|c|}{2014} & \multicolumn{3}{|c|}{2015} & \multicolumn{3}{|c|}{ Combined (2014 - 2015) } \\
\hline PAN 3408 & $77.35 \pm 0.51 \mathrm{de}$ & $75.37 \pm 1.29^{a}$ & PAN 3408 & $79.88 \pm 0.46^{\text {bcde }}$ & $79.40 \pm 0.55^{a b}$ & PAN 3408 & $78.61 \pm 0.33^{\mathrm{cd}}$ & $78.00 \pm 0.72^{b}$ \\
\hline PAN 3515 & $80.93 \pm 0.51^{a}$ & $79.94 \pm 1.13^{a}$ & Ratel & $80.25 \pm 0.46$ abcd & $79.57 \pm 0.56^{a b}$ & Ratel & $77.45 \pm 0.33^{d}$ & $78.05 \pm 0.91^{b}$ \\
\hline Ratel & $74.65 \pm 0.51^{f}$ & $76.04 \pm 1.22^{a}$ & SST 0117 & $78.73 \pm 0.46 \mathrm{de}$ & $77.96 \pm 0.55^{b}$ & SST 0127 & $77.96 \pm 0.33 \mathrm{~cd}$ & $78.28 \pm 0.50 \mathrm{ab}$ \\
\hline SST 0127 & $78.08 \pm 0.51$ bcde & $77.86 \pm 1.12^{a}$ & SST 0127 & $77.85 \pm 0.46^{\mathrm{e}}$ & $79.16 \pm 0.55 \mathrm{ab}$ & SST 015 & $79.45 \pm 0.33 \mathrm{bc}$ & $78.85 \pm 0.22 \mathrm{ab}$ \\
\hline SST 047 & $80.15 \pm 0.51 \mathrm{abc}$ & $80.10 \pm 1.19^{a}$ & SST 027 & $82.25 \pm 0.46^{a}$ & $81.28 \pm 0.566^{a b}$ & SST 087 & $77.59 \pm 0.33^{d}$ & $78.24 \pm 0.71 \mathrm{ab}$ \\
\hline SST 056 & $78.25 \pm 0.51$ bcde & $76.38 \pm 1.09^{a}$ & SST 056 & $78.85 \pm 0.46$ cde & $80.55 \pm 0.55^{a b}$ & SST 096 & $79.04 \pm 0.33^{\mathrm{cd}}$ & $78.95 \pm 0.55^{a b}$ \\
\hline SST 087 & $76.33 \pm 0.51$ ef & $76.68 \pm 1.47^{a}$ & SST 087 & $78.85 \pm 0.46$ cde & $79.65 \pm 0.56$ ab & SST 88 & $78.9 \pm 0.33^{c d}$ & $78.35 \pm 0.59 a b$ \\
\hline SST 096 & $78.70 \pm 0.51$ abcde & $77.26 \pm 1.29 \mathrm{a}$ & SST 096 & $79.38 \pm 0.46 \mathrm{c}^{\mathrm{de}}$ & $79.71 \pm 0.56 a b$ & Tankwa & $79.46 \pm 0.33^{b c}$ & $79.40 \pm 0.44^{\mathrm{ab}}$ \\
\hline SST 88 & $77.35 \pm 0.51$ de & $77.10 \pm 1.17 \mathrm{a}$ & SST 88 & $80.45 \pm 0.46$ abcd & $79.81 \pm 0.56 \mathrm{ab}$ & & & \\
\hline
\end{tabular}

Means depicted by the same alphabetic letter within a column do not differ significantly $(\mathrm{P}<0.05)$ 
Table 6 Power analysis of yield and hectolitre mass for cultivar ('Gen') evaluation trials laid out as a randomised complete block design (RCBD) and a latinised row-column design (LRCD) in the 2014, 2015 and combined years.

2014

2015

Combined 2014-2015

\begin{tabular}{|c|c|c|c|c|c|c|c|c|}
\hline \multirow{2}{*}{ Yield } & \multirow[t]{2}{*}{ RCBD } & \multirow[t]{2}{*}{ LRCD } & \multirow[t]{2}{*}{ RCBD } & \multirow[t]{2}{*}{ LRCD } & \multicolumn{2}{|c|}{ RCBD } & \multicolumn{2}{|c|}{ LRCD } \\
\hline & & & & & & & & \\
\hline Effect & Gen & Gen & Gen & Gen & Gen & Year*Gen & Gen & Year*Gen \\
\hline Genotype degrees of freedom & 13 & 13 & 13 & 13 & 11 & 12 & 11 & 12 \\
\hline Error degrees of freedom & 39 & 13.3 & 39 & 11.9 & 66 & 66 & 52 & 52 \\
\hline Calculated $\mathrm{F}$ value & 10.9 & 24.3 & 2.7 & 5.3 & 8.9 & 16.2 & 8.0 & 5.9 \\
\hline Probability of $F$ value & $<0.001$ & $<0.001$ & 0.001 & 0.004 & $<0.001$ & $<0.001$ & $<0.001$ & $<0.001$ \\
\hline Alpha - Type I error probability & 0.05 & 0.05 & 0.05 & 0.05 & 0.05 & 0.05 & 0.05 & 0.05 \\
\hline Critical $F$ value & 1.98 & 2.55 & 1.98 & 2.67 & 1.94 & 1.90 & 1.99 & 1.94 \\
\hline Power (1-Beta or 1-Type II error probability) & 1.00 & 1.00 & 0.95 & 0.98 & 1.00 & 1.00 & 1.00 & 1.00 \\
\hline \multicolumn{9}{|l|}{ Hectolitre mass } \\
\hline Effect & Gen & Gen & Gen & Gen & Gen & Year*Gen & Gen & Year*Gen \\
\hline Genotype degrees of freedom & 13 & 13 & 13 & 13 & 11 & 12 & 11 & 12 \\
\hline Error degrees of freedom & 39 & 12 & 39 & 11 & 66 & 66 & 12 & 12 \\
\hline Calculated $\mathrm{F}$ value & 11.24 & 8.95 & 7.0 & 5.0 & 12.3 & 8.6 & 8.1 & 2.2 \\
\hline Probability of $F$ value & $<0.001$ & $<0.001$ & $<0.001$ & 0.006 & $<0.001$ & $<0.001$ & $<0.001$ & 0.100 \\
\hline Alpha - Type I error probability & 0.05 & 0.05 & 0.05 & 0.05 & 0.05 & 0.05 & 0.05 & 0.05 \\
\hline Critical $F$ value & 1.98 & 2.66 & 1.98 & 2.76 & 1.94 & 1.90 & 2.72 & 2.69 \\
\hline Power (1-Beta or 1-Type II error probability) & 1.00 & 1.00 & 1.00 & 0.96 & 1.00 & 1.00 & 1.00 & 0.64 \\
\hline
\end{tabular}




\section{Discussion}

Agronomists and plant breeders prefers RCBD because of its simplicity and familiarity. However, RCBD does not account for spatial heterogeneity in more than one direction. On the other hand, LRCD takes trial variation of two directions into account.

For most of the parameters included in these experiments, the LRCD produced results that are more reliable, in contrast to the findings of Shah et al. (2017). Grain yield is one of the most influential traits to consider when choosing a wheat cultivar. For grain yield, the LRCD specifically had a smaller experimental variance (MSE $\left(\sigma^{2} E\right)$ and a lower $\mathrm{CV}$ and higher $\mathrm{R}^{2}$ than the RCBD. The relative design efficiency confirmed that the LRCD was the better design in the separate and combined years. Whereas the mean repeatability estimates $(\mathrm{BSH})$ in the $\mathrm{RCBD}$ were higher in the separate years and LRCD were slightly higher in the combined years probably due to the genotype by year interaction that was not significant.

Hectolitre mass is mostly correlated to starch in a more favourable season. A higher hectolitre mass, associated with good kernel fill and plumpness, which indicates better wheat quality. The hectolitre mass is influenced more by environmental factors than any of the other grain quality parameters (Miles 2018). During the two-year study, we noted that there were hectolitre mass differences between the individual years and the combined results when comparing RCBD and LRCD. The relative design efficiency results for hectolitre mass showed that LRCD was the better design in 2015, while RCBD was better in 2014 and in the combined year analysis.

The repeatability measured on mean basis $(\mathrm{BSH})$ for hectolitre mass showed higher values in the separate years for the RCBD than for the LRCD. While the LRCD showed a higher repeatability value in the combined year analysis. This may be due to a non- 
significant interaction effect of genotype by year (the variance component is 0 ). This indicates that the genotypes reacted similarly over the two years for the LCRD.

\section{Conclusion}

Although the LRCD produced higher $\mathrm{R}^{2}$, lower $\mathrm{CV}$ and MSE results than the RCBD, the mean repeatability (BSH) was only higher in the LRCD in the combined years for both yield and hectolitre mass. Comparing these designs with each other using the relative efficiency of the designs the LRCD is the better design for hectolitre mass in 2015. Whereas for grain yield which is the primary trait in cultivar evaluation trials the LCRD is the better design in the separate and combined year analyses. Furthermore, it was shown that LRCD with four block replicates was more efficient than the RCBD with four blocks replicates using the AIC and BIC values. Although the power analyses could not show a preferred design, this analysis should not be ignored as many research do. We therefore recommend the use of LRCD in preference to RCBD in cultivar trials.

\section{Acknowledgements}

Appreciation goes to Mr Willem Kilian and Mr Willem Botes for supporting and allowing the main author to complete his studies. Special thanks to Lee Saul for the support and encouragement. The ARC Small Grain-Stellenbosch is acknowledged for funding this project.

\section{References}

Annicchiarico P. 2002. Genotype x Environment Interactions - Challenges and Opportunities for Plant Breeding and Cultivar Recommendations. Plant production and protection papers No 174, Food and Agriculture Organization of the United Nations, Rome. 
Bartlett MS. 1937. Properties of sufficiency and statistical tests. Proceedings of the Royal Statistical Society, Series A 160, 268-282

Burgueno J, Cadena A, Crossa,J, Banziger M, Gilmour AR, Cullis B. 2000. User's Guide for Spatial Analysis of Field Variety Trials Using ASREML. Mexico, DF: CIMMYT.

Campbell KG, Thompson YM, Guy SO, Mclntosh M, Glaz B. 2015. "Is, or is not the great ends of Fate": Errors in Agronomic Research. Agronomy Journal 107:718729

Crossa J. 1990. Statistical analyses of multilocation trials. Advances in Agronomy 44: $55-85$

Falconer DS, Mackey TFC. 1996. Introduction to Quantitative Genetics. $4^{\text {th }}$ Ed Longman Group Ltd, Malaysia.

Fisher RA 1926. The arrangement of field experiments. Journal of Ministry of Agriculture 33:503-513

Levene H. 1960. Contributions to probability and statistics: essays in honor of Harold Hotelling. In: Robust test in the equality of variance. I Olkin (Ed) pp. 278-292. Stanford, UP.

Miles CW. 2018. Relationships between mixsmart parameters and bread wheat quality characteristics in South African dry land cultivars. Doctoral dissertation, University of the Free State, Bloemfontein, South Africa.

Pakendorf KW. 1977. A study on the efficiency of current methods of breeding and testing for wheat improvement in the Western Cape Province. Doctoral dissertation, Stellenbosch University, Stellenbosch, South Africa. 
Piepho HP, Möhring J. 2007. Computing heritability and selection response from unbalanced plant breeding trials. Genetics 177: 1881-1888.

Piepho HP, Williams ER, Michel V. 2015. Beyond Latin Squares: A brief tour of Rowcolumn designs. Agronomy Journal 107: 2263-2270.

Shah SAA and Khan AM. 2017. Comparative Efficiency of Randomized Complete Block Design Vs. Latin Square Design in Wheat Yield Trial. Journal of Natural Sciences Research 7: 22-25.

Shapiro SS, Wilk MB. 1965. An analysis of variance test for normality (complete samples). Biometrika 52: 591-61.

Soil Classification Working Group. 1991. Soil Classification: a taxonomic system for South Africa: Memoirs on the agricultural natural resources of South Africa No. 15. Pretoria, South Africa: Department of Agricultural Development.

Swanepoel PA, le Roux PJG, Agenbag GA, Strauss JA, MacLaren C. 2019. Seed-drill opener type and crop residue load affect canola establishment, but only residue load affects yield. Agronomy Journal 111: 1-8 (In Press).

Vargas M, Combs E, Alvarado G, Atlin G, Matthews K, Crossa J. 2013. META: A Suite of SAS Programs to Analyze Multi-environment Breeding Trials. Agronomy Journal 105: 11-19.

Whitaker D, Williams ER, John JA. 2002. CycDesigN: a package for the computer generation of experimental designs. University of Waikato, Hamilton, NZ.

Williams ER, John JA, Whitaker D. 2006. Construction of resolvable spatial rowcolumn designs. Biometrics 62:103-108. 